Article

\title{
Aesthetical Appeal and Dissemination of Architectural Heritage Photographs in Instagram
}

\author{
Vicente López-Chao ${ }^{1, *(D)}$ and Vicente Lopez-Pena ${ }^{2}$ \\ 1 Architectural Graphics Department, School of Architecture, Universidade da Coruña, 15008 A Coruña, Spain \\ 2 Department of Mechanical Engineering and Industrial Design, Faculty of Engineering, \\ Campus de Puerto Real, Universidad de Cádiz, 11003 Cádiz, Spain; vicente.lopez@uca.es \\ * Correspondence: v.lchao@udc.es
}

Received: 31 October 2020; Accepted: 1 December 2020; Published: 3 December 2020

check for updates

\begin{abstract}
Image-based social networks are environments where users share their photographs and involuntarily contribute to evolve and to spread the meaning of things. For this reason, it is essential to use this source of information to determine how people perceive cultural heritage, specifically building heritage. These interactive spaces have a visual component that is essential to understand users' perception of heritage architecture and that may also influence the dissemination of images. This research aims to describe the social concept of architectural heritage on Instagram and to explore whether the aesthetic appeal resources influence its dissemination. Images indexed to the hashtag \#patrimonioarquitectonico (Spanish language version of \#architecturalheritage) were collected for the period of three months ( $\mathrm{n}=180$ images). A graphical and observational analysis was performed on categories of four variables of aesthetical appeal: human dimension, color, linear perspective and aesthetical quality. Subsequently, descriptive, cross-tabulation and variance analyses were applied. The findings have proven that regular users share a fairly heterogeneous vision of building types concerning architectural heritage, and that there are stakeholder accounts that could be altering their meaning due to strategies to protect residential areas. The paper describes how the aesthetic appeal variables add meaning to the social perception of the building heritage and which ones statistically influence its dissemination in terms of likes and engagement on Instagram.
\end{abstract}

Keywords: architecture; architectural graphics; building; built environment; culture; drawing; representation; visual balance

\section{Introduction}

Social networks have been established as the digital means to share information with an unimaginable population scope, greatly expanding human interaction [1]. This situation arises in a process of normalization of the use of mobile devices with internet access in the last decade. Both conditions entail ubiquity, that is, information can be shared from anywhere. Moreover, it requires a small screen size that benefits the display of visual content over textual content [2]. Specifically, Instagram has become one of the most successful and popular applications because it provides a feeling of closeness and immediacy [3], and it has a high participation rate [4].

In this platform, there is a type of users called influencers, who are capable of causing an effect on the behavior [5] and thinking of their followers about different real situations, such as sustainability in tourism [6]. Meanwhile, the regular user consumes a lot of information in a short time to stay up-to-date on trends, rather than digging into content. User retains subliminal messages (i.e., brand or song advertisements) that may change their perception regarding any topic.

Besides, users index their images through written codes known as hashtags (terms preceded by the \# symbol), to disseminate their pictures in thematic niches [7]. This social fact brings 
together a multitude of experiences and perspectives on a term leading to a collective memory [8], which feeds on cultural differences about the topic and how the photograph should be to transmit it [9]. Thus, previous findings suggest that image-based social networks (IBSNs) are valuable sources of information to better understand the world [10].

IBSNs provide new avenues to interact with architectural heritage that affect its interpretation [11]. Images posted on IBSNs indicate users' interest in a particular perspective and incorporate what they want to remember in the future. This collaborative vision is essential to support the identity of architectural heritage as a tool to display its value, while its loss could lead to the disappearance of social identity and community cohesion [12].

It seems that a cultural product is no longer defined by academics, which has drawn attention to studies on heritage in social networks [13]. Architecture provides a social value in its tectonic and in its capacity to host cultural practices. IBSNs incorporate their social importance through the contributions of each user on how they live, understand and value their heritage [14].

This graphic database is interesting and suitable to perform a critical review on the contributions of the collective vision on architectural heritage, displacing the academic imaginary towards inhabiting architecture [15]. As Anadol stated (p. 82), "despite what is seemingly a lack of social awareness as users concentrate on their screens, photogenic architecture and media content can provide opportunities to allow alternative interactions with people and environments" [16], so it can be an opportunity to attract people to the place both physically and virtually [17].

The literature related to IBSNs is very recent, since those works have been used popularly for half a decade. In this way, Instagram is currently one of the most important social information carriers, and, for now, the institutions have not considered it to disseminate cultural content. Then, this research rises the following questions. What is the visual image of architectural heritage that Instagram users disseminate collaboratively? Do aesthetical appeal features influence the dissemination of this visual message? In order to solve these questions, the manuscript is structured in four sections:

- Section 2 deals with the literature background concerning the technical elements of the research, mainly focused on visual resources of building photos posted on Instagram. It includes the image social meaning generation in IBSN, the aesthetical appeal of pictures (referred to color and composition) and the dimension of human being in architecture.

- Section 3 covers the materials and methods, including the explanation of the non-experimental research design, to analyze the social perception of architectural heritage on Instagram, as well as how the aesthetic appeal of pictures influence their dissemination within the social network. It also describes the research variables and how they were categorized, comprising the Instagram user profile, the degree of dissemination, the typology of architectural heritage and the aesthetical appeal features of the picture.

- Section 4 addresses the results based on statistical analysis which mainly focus on two types of analyses. First, contingency tests offer the description of the message depending on the Instagram user profile. Second, non-parametric tests assess whether the aesthetical appeal features are related to the degree of dissemination of architectural heritage pictures.

- Section 5 provides a discussion on the findings in relation to the literature, and some practical actions are provided so government agents can promote the conservation of architectural heritage through image-based social networks. These proposals incorporate both the replication of the research method to diagnose the degree of visibility of a specific case and the application of the aesthetical appeal features.

\section{Literature Background}

\subsection{Image Social Meaning Generation}

According to the theories of hermeneutical interpretation, the photograph of a heritage element entails the photographer's approach, being able to record different readings and expressions. At the 
same time, IBSN users may also interpret the image differently than the photographer's intention, which will expand the identity of that heritage site. Other factors that can alter perception are image editing tools [18] and the distribution of geographic participation, which has proven to be important in promoting places [19].

Previous research has observed small deviations from the dominant and orthodox perception of heritage [20]. However, these findings are based on a single case study and on more controlled web spaces in terms of collaborative content creation, such as Wikipedia or Facebook, which are very different from Instagram. Others have used this IBSN to document the spatial trends of citizens on their use and perception of urban nature through the content of \#sharingcph [21]. The authors noted that this source is very powerful to generate, share, visualize and communicate knowledge and to support scientific and democratic interaction. Likewise, these geo-located data are useful for designing human-centered landscapes by monitoring IBSN users' actions in public spaces [22].

However, the images are not evenly distributed, but rather related to their visual (aesthetical appeal) or social (message) interest. Now the perception of an image is related to the number of followers or the capacity to engage of the user who uploads the picture. Engagement is understood in online marketing as the degree of emotional involvement that the followers of an account and its content have-in other words, their degree of loyalty. When researching IBSN it is essential to consider this commitment, as users actively participate when sharing and commenting on photos [23].

In any case, these open and virtual databases allow for the gathering of the popular image [19], to understand the people's opinion on a subject. However, stakeholders can modify information on social networks and consequently improve their image and participation, as in the case of promoting tourist destinations [24]. The European Union is aware of the need to participate in digital environments to spread messages about heritage and culture [25]. In fact, they have proposed several actions that promote the use of websites and augmented reality for this purpose. However, their attention has not yet reached social networks like Instagram. This research tries to anticipate this gap, to diagnose the image of architectural heritage on Instagram with the objective that public institutions promote its appropriate dissemination in environments that citizens use.

\subsection{Aesthetical Appeal: Color and Composition}

Regarding aesthetical appeal, color and composition are essential features that influence perception. Color is considered one of the visual elements that most influence [26] and can affect the emotions and behaviors of individuals [27], since its intensity can shape the meaning of the photograph [28]. Thus, city pictures that contain colors such as orange, yellow or red on Instagram obtained a greater number of likes [29]. It also denotes preferences in social networks [30], since users can base on color criteria which photos they share. The preference towards a particular one is related to other factors, such as personality or gender across different cultures [31], and it can reveal feelings that written publications cannot [32,33], being the affective issue essential in everything related to heritage. Specifically, cold-tone images inspire calm and reflection and provide an impression of greater distance than those with warm ones [34].

On the other hand, composition or visual balance [35] refers to how the visual interest of an image is distributed [36-38] based on contrapositions of luminance and geometric patterns [39], such as the rule of thirds, visual balance, simplicity and diagonal dominance $[40,41]$. The rule of thirds is one of the most popular and is defined as a simple approach to the Golden ratio, whereby an element is positioned in an area of the image that provides greater interest or tension. These places correspond to the imaginary lines (vertical and horizontal) to a third of the perimeter of the photo that creates four points of an intersection known as power points. Figure 1a shows how this alignment method supports a focal point that hold the viewer's attention. Dominance diagonal is used to generate a dynamic feel in the image, in which each side of an image is divided into two equal 45-degree angles to form the bisection lines, where the most important part of the image should be placed. This corresponds with the case of the Figure $1 b$, although the diagonal does not divide the image at 45 degrees. It is the visual 
resource that provides more harmony because there is a compensation of perceptual forces. Symmetry, asymmetry, radial and mosaic are the types of visual balance.

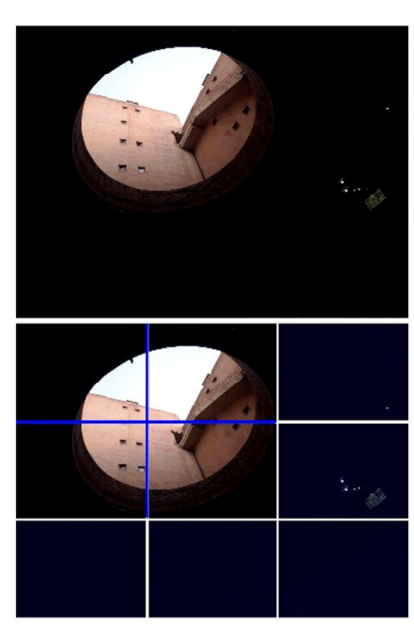

a

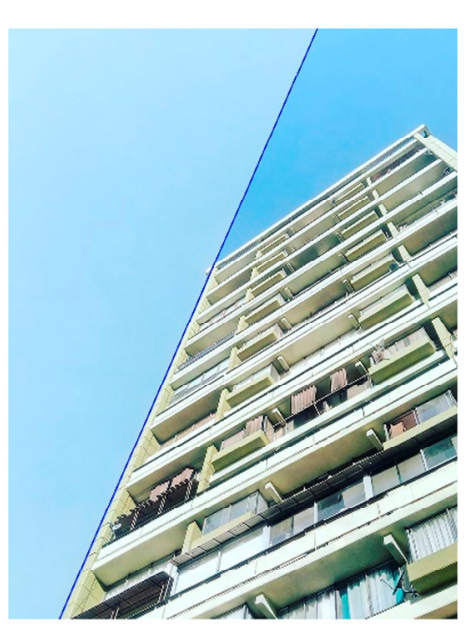

b

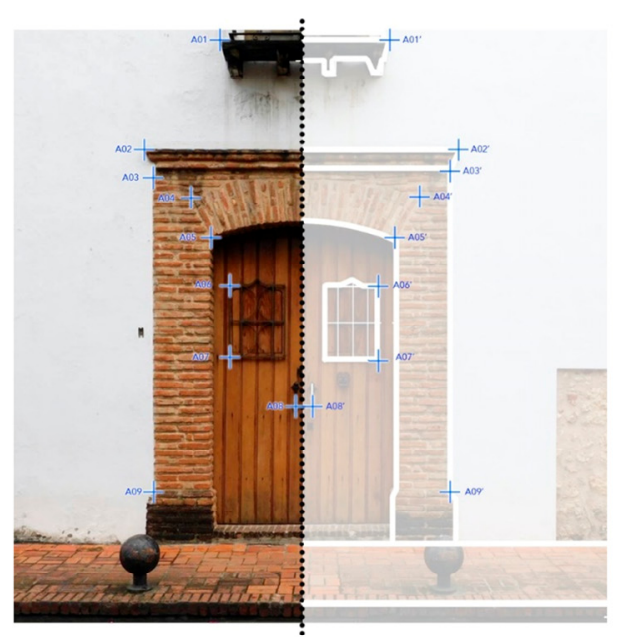

c

Figure 1. Examples of composition analysis of architectural heritage pictures collected from \#patrimonioarquitectonico in Instagram: (a) Rule of thirds, the focal point corresponds with the intersection of the blue lines. Font: edited from original (elperrusquinho). (b) Dominance diagonal, the blue line clarifies the two areas of the picture which matches one of the vanishing edges. Font: edited from original (jm_ac). (c) Symmetry, reference points demonstrate near-perfect vertical symmetry. Font: edited from original (fachadasrd).

It has been found that symmetry patterns are cognitively processed more quickly [42] (see example in Figure 1c), as well as that the absence of balance requires more attention [43]. Some authors have evidenced the use of visual composition trends on Instagram by artists and non-artists with respect to "eye-centring" in the composition of a selfie [44], indicating that "possibly related to organizational principles governing our perception of balance in a composition, rather than on socio-culturally learned rules" (p. 8). Specifically, regarding the aesthetical appeal of architectural photographs, Thömmes and Hübner found that visual balance precedes a greater number of likes in more complex three-dimensional photographs [45]. Hsieh, Hsu and Wang [46] explored the attraction of images in networks towards the user, in terms of visual and social aspects. As a result, they found that the most shared images are not necessarily aesthetic, despite the fact aesthetic images are more likely to be visually interesting to people. Furthermore, the aesthetical appeal of images has been shown to be a measurement element that predicts the number of likes quite well [47].

\subsection{Human Figure and Architecture}

Furthermore, in the representation of architecture, the reference to the human dimension has always been relevant based on its anthropometric origin [48]. Among the objectives of including people in architectural spaces, they are to show and transmit the cultural values of an era and to merge the architectural project with its surroundings [49]. In this way, the human figure is a key element to highlight architectural content and to communicate the characteristics of a natural or built space.

Thus, linear perspective is the communication system in which the human figure finds its natural channel to highlight the perception of spatial contents [49]. However, even more importantly, it can help convey the effects that buildings have on people, as well as the role that people play in shaping their environments. Therefore, it is a powerful tool to conceive and represent architecture [50], which gives different messages to architectural thinking [51]. This importance has led to studies on their presence in IBSN images, in which it is noted that those that contain people's faces receive $38 \%$ more likes [4]. In this case, the presence of the human figure as a communication resource can provide 
a different vision both for reasons related to content sharing strategies on social networks and the meaning of the user on architectural heritage.

In short, these questions raise the need to consider, on the one hand, both the number of likes and the engagement, since there is an underlying social behavior that could influence the dissemination of the image beyond its aesthetic qualities. On the other hand, it will be necessary to corroborate the presence of stakeholders that can promote a biased image of architectural heritage. In addition, it will be essential to evaluate the impact of the composition and color range of the photos, since they can provide valuable information on how the photo is socially built and on feelings and emotions towards heritage. Finally, the human dimension provides spatial information to understand the relationship between people and architecture.

\section{Materials and Methods}

This paper aims to describe the social concept of architectural heritage on Instagram and to explore whether the aesthetic appeal resources influence its dissemination. Thus, should this occur, the authorities could refer to the results of this research to reach the popular audience through heritage awareness policies in image-based social networks. For this, the manuscript focuses on the application of a non-experimental research design under a quantitative approach by indirect observation.

The information under study was collected in the hashtag \#patrimonioarquitectonico (the Spanish language version of \#architecturalheritage) of the social network Instagram during a period of three months. The sample consists of 180 images that were registered with their information related to engagement (number of likes and followers of the account) and their Uniform Resource Locator (to ensure future access to the images) in an offline database. Some images $(n=40)$ were eliminated because they referred to future meetings on heritage through written messages. Subsequently, the images were categorized according to the typology of architectural heritage and various aesthetic appeal features (human dimension, color, type of perspective and aesthetic quality).

Contingency analyses were applied on the type of building and user account, to describe what message is being spread and by whom. Consecutively, normality tests were applied on the number of likes and engagement, to find out what type of analysis of variance was necessary. The results led to the use of non-parametric tests to explore whether there are statistically significant differences in the number of likes or engagement according to any of the previously mentioned graphic resources. Finally, Tukey's test was run in some cases, to find out between which categories differences occur.

\section{Variables}

The degree of dissemination of the images is measured with two dependent variables that are collected from the social network: the number of likes and engagement (calculated as the number of followers divided by the number of likes of the image). In addition, Instagram users were differentiated according to the type of account: regular user and stakeholder. This is because they could be promoting different meaning of building heritage due to the defense or conservation of a certain environment. To do this, the description and name of the account and its last twenty photos were reviewed. Regarding the content, a description is given of the building typologies and architectural elements that the users share the most.

The aesthetical appeal variables are human dimension, color, type of perspective and aesthetic quality and are obtained through graphic overlay analysis and observation analysis on the images.

The human dimension was categorized according to the human absence or presence in the picture. Research mentioned previously recorded the action or posture of the person in the images, the surface they occupied on the canvas or the number of people. In this case, the variable is conceived as a graphic resource that provides dimension to architecture, shedding light on whether users convey a vision of heritage close to or far from people (Figures 2 and 3 provide some architectural heritage pictures including and avoiding the human dimension). The nomenclature chosen to refer to the presence of people is controversial, since there are elements with more or less standard 
measures that provide a human dimension without the presence of people, such as windows or doors. However, heritage architecture may have been conceived according to non-anthropocentric proportions (i.e., Figure $1 b$ ). In addition, the human figure provides other connotations beyond the measurements, as mentioned above.

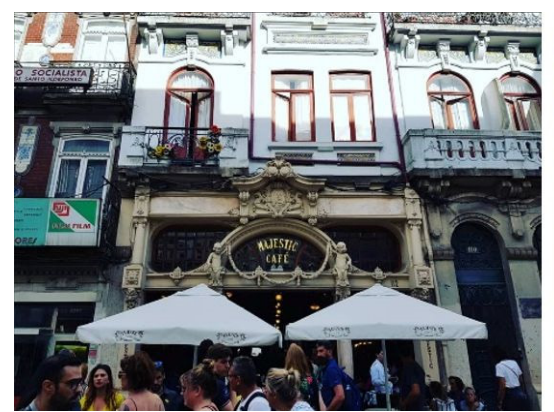

(a)

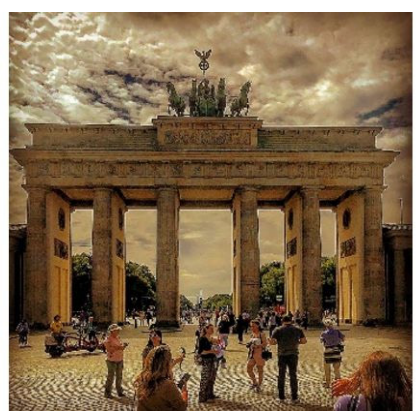

(b)

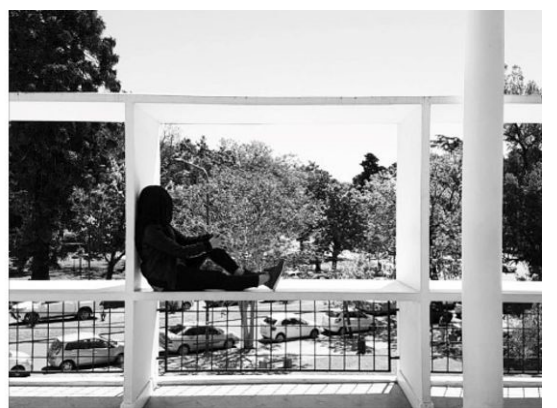

(c)

Figure 2. Architectural heritage pictures collected from \#patrimonioarquitectonico in Instagram with human dimension: (a) font, celinaaida; (b) font, pedrodelrealc; (c) font, angelacarvajalf.

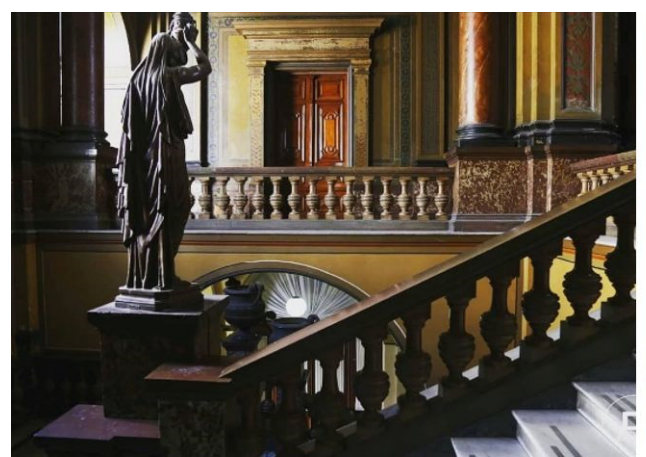

(a)

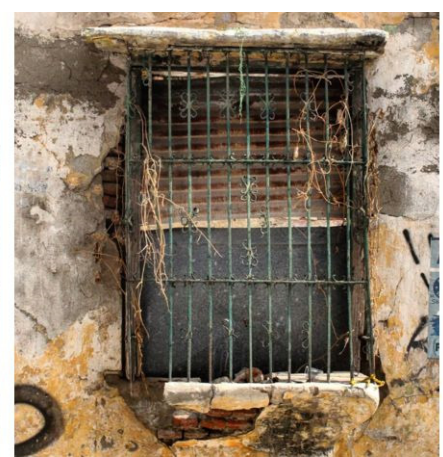

(b)

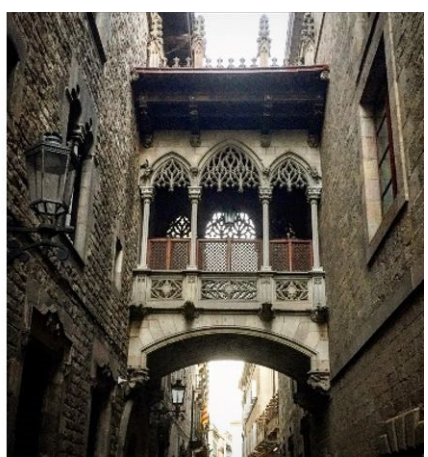

(c)

Figure 3. Architectural heritage pictures collected from \#patrimonioarquitectonico in Instagram without human dimension: (a) font, alberto_direnzo_fotografias; (b) font, fachadas_de_santa_marta; (c) font, nunorebeloarq.

The color feature was categorized according to three possibilities: cool tones, warm tones and grayscale. This decision is based on the nature of the proximity that color brings. Those images in warm tones bring a message closer to people's lives, and those in grayscale transmit a distancing, even in history, as an element of the past (see examples in Figure 4).

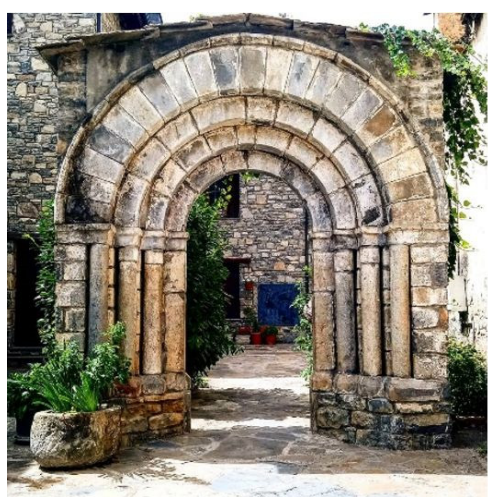

(a)

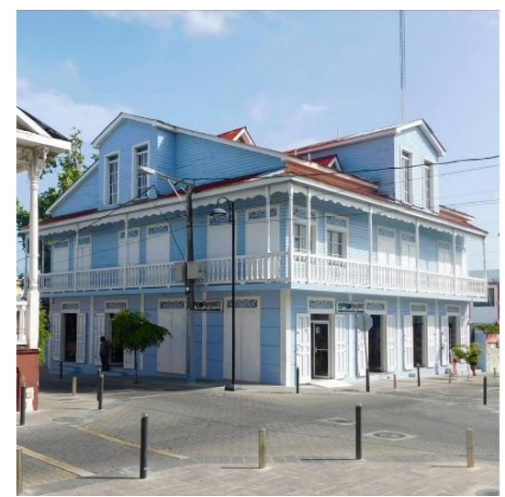

(b)

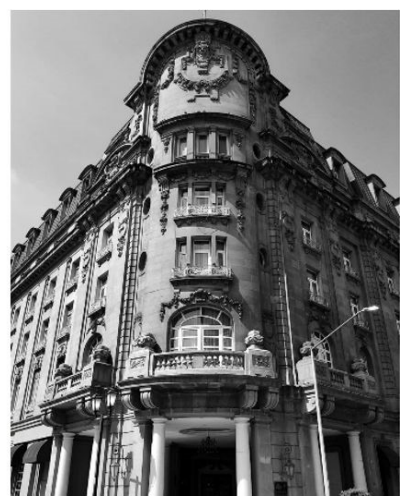

(c)

Figure 4. Architectural heritage pictures collected from \#patrimonioarquitectonico in Instagram regarding color: (a) font, muntsa33; (b) font, achadasrd; (c) font, jslzrrz. 
The type of linear perspective is a novelty in IBSN image research that seeks to identify an important source of representation related to the size of mobile device screens. In applications like Instagram, users swipe images to access more content without zooming. The importance lies in the degree of immersion that the type of perspective can produce in the user on screens between 5 " and 6.5" average. The screen size is essential because IBSNs are popular on small devices; in fact, on the computer, it does not even allow the uploading of photos. Frontal perspectives $(1$ vanishing point perspective-1VPP) is the typology that allows a greater immersion, while 2 vanishing points perspective (2VPP) provides a perception of distance and 3 vanishing points perspective (3VPP) faces an intermediate scenario in terms of immersion but more extreme considering the fact of the deformation of the element to be transmitted (see examples in Figure 5).

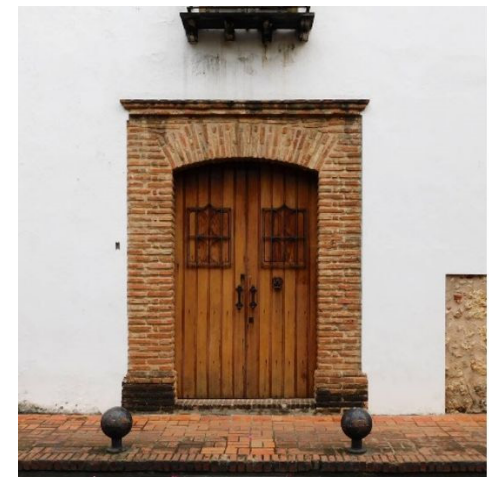

(a)

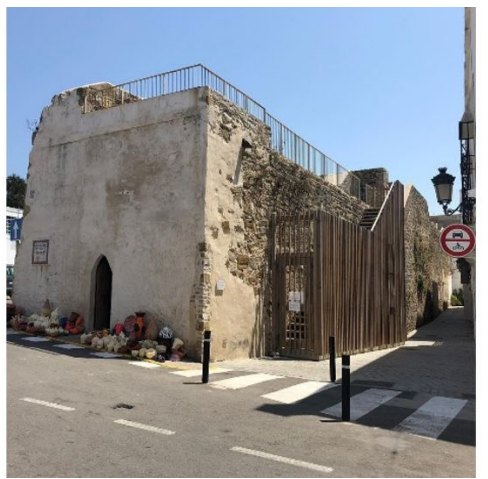

(b)

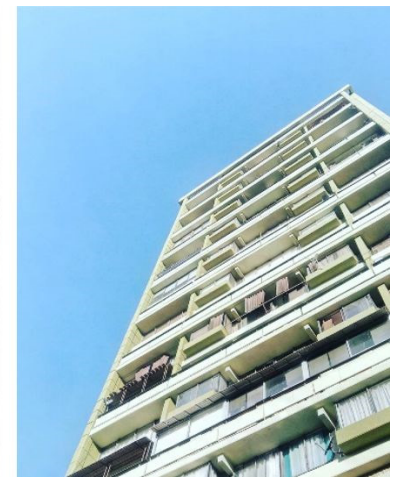

(c)

Figure 5. Architectural heritage pictures collected from \#patrimonioarquitectonico in Instagram regarding types of linear perspective: (a) font, fachadasrd; (b) font, fedeidola; (c) font, jm_ac.

The aesthetic quality is mainly based on visual balance; however, considering that the average user is not a professional of design or photography, it is proposed to classify this category into three levels (see examples in Figure 6): low, when the picture does not follow compositional technique and is unintentionally twisted or out of focus; medium, when the image shows signs of having foreseen popular composition, such as the rule of thirds; and high, when the image combines compositional techniques and artistic purpose (e.g., intentional blur/macro, etc.).

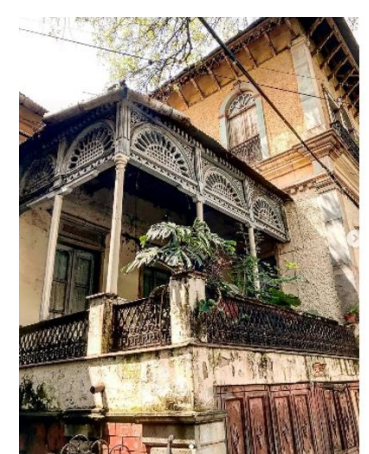

(a)

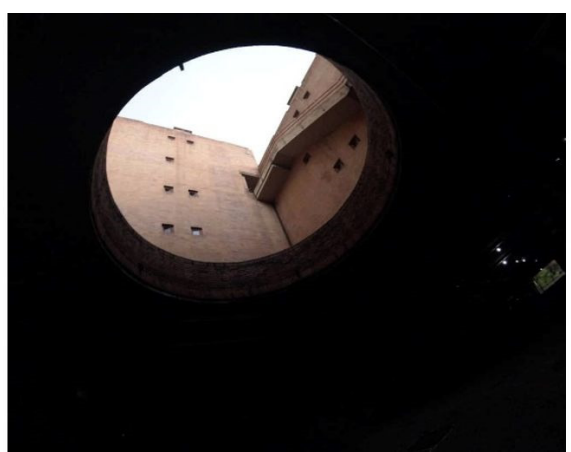

(b)

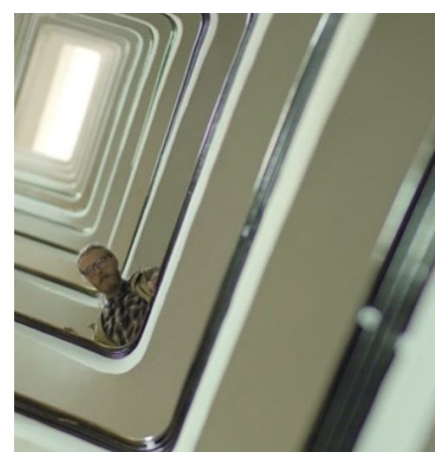

(c)

Figure 6. Architectural heritage pictures collected from \#patrimonioarquitectonico in Instagram regarding types of aesthetical quality: (a) font, rebecca_arq; (b) font, elperrusquinho; (c) font, konstruktion_argentina.

Therefore, the research has sought to adapt to the way this image-based social network works, considering the aforementioned social and visual variables. Next, the results of the statistical analyses on information from Instagram architectural heritage photographs are provided, which allows us to evaluate the message and the influence on its dissemination in this collaborative environment. 


\section{Results}

\subsection{Building Typology, Element Detail and User Account: Contingency Analysis}

In the first place, a descriptive analysis was applied through a cross-tabulation, to display the frequency distribution of the variables building and Instagram user. The results indicate that the three most representative categories of architectural heritage in the social network represent 70.1 percent of the images (see Figure 7): residential (37.10\%), urban (17.86\%) and religious (15.71\%), while the museum represent 6.43 per cent. The category "others" comprise cases with lower frequency than 5 percent in any account type, such us market, hotel, military (including citadel and palaces), skyscraper, archaeology, cultural (cinema, theatre, sportive), hospitals, government and industrial. Regarding account typology, residential buildings are the main message from stakeholders, while regular user accounts distribute the contributions in more categories.

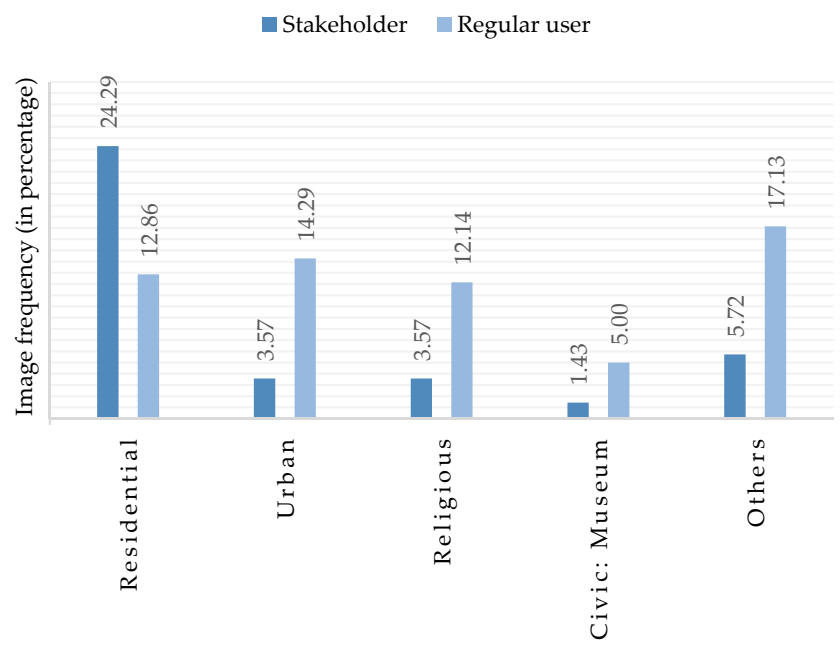

Figure 7. Bar graph on building-type frequency by Instagram user account.

Subsequently, the same type of analysis was run to describe which elements or parts of the heritage architecture are the focus of attention (see Figure 8). In the stakeholder accounts, facades represent almost half of the sample (45\%); a second group of elements is around 10 per cent (ruins $12.71 \%$, details $10 \%$, cities $8.57 \%$ windows $8.57 \%$ and indoors $7.86 \%$ ), while there is a third category with lower frequency than 5 percent (doors $4.29 \%$, views $2.14 \%$ and $1.43 \%$ structures). The difference per user follows a similar pattern to the previous case, and stakeholder accounts focus on facades (and less on windows), while regular user distribute their attention to a wider range of elements, such as a symbol of heritage.

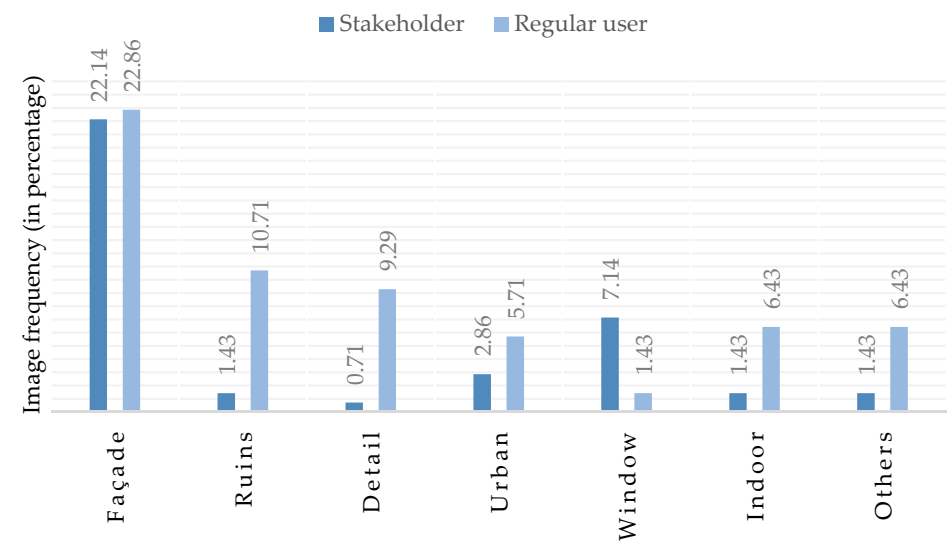

Figure 8. Bar graph on architectural-element frequency by Instagram user account. 


\subsection{Normality and Variance Test}

Before applying the variance tests, it is necessary to evaluate the type of distribution of the sample. For this reason, the Kolmogorov-Smirnov test was run on the dependent variables, likes and engagement, with the aim of knowing their distribution in the categories of the aesthetical appeal variables. The results indicate that some category does follow a normal distribution. However, none of the variables has a normal representation for all its categories (see Table 1). Therefore, non-parametric analyses were applied.

Table 1. Kolmogorov-Smirnov test results (dependent variables: likes and engagement).

\begin{tabular}{cccccccc}
\hline \multirow{2}{*}{ Variable } & \multirow{2}{*}{ Categories } & \multicolumn{3}{c}{ Likes Test Results } & \multicolumn{3}{c}{ Engagement Test Results } \\
\cline { 3 - 7 } & & Statistic & df & Sig. & Statistic & df & Sig. \\
\hline \multirow{2}{*}{ Human dimension } & Presence & 0.347 & 29 & 0.000 & 0.210 & 29 & 0.002 \\
& Absence & 0.199 & 111 & 0.000 & 0.079 & 111 & 0.087 \\
\hline \multirow{3}{*}{ Color } & Greyscale & 0.194 & 13 & 0.195 & 0.186 & 22 & 0.046 \\
& Warm & 0.164 & 63 & 0.000 & 0.081 & 93 & 0.169 \\
& Cold & 0.238 & 16 & 0.016 & 0.096 & 25 & 0.200 \\
\hline \multirow{3}{*}{ Linear perspective } & 1VPP & 0.206 & 38 & 0.000 & 0.086 & 57 & 0.200 \\
& 2VPP & 0.227 & 41 & 0.000 & 0.159 & 63 & 0.000 \\
& 3VPP & 0.418 & 13 & 0.000 & 0.126 & 20 & 0.200 \\
\hline \multirow{3}{*}{ Aesthetic quality } & Low & 0.259 & 60 & 0.000 & 0.111 & 60 & 0.065 \\
& Medium & 0.292 & 60 & 0.000 & 0.125 & 60 & 0.020 \\
& High & 0.261 & 20 & 0.001 & 0.183 & 20 & 0.078 \\
\hline
\end{tabular}

Notes: 1VPP, one vanishing point perspective; $2 \mathrm{VPP}$, two vanishing points perspective; 3VPP, three vanishing points perspective. $\mathrm{df}=$ degree of freedom; sig. = statistical significance.

Afterwards, several variance analyses were carried out to detect whether the variable likes obtained different amounts of statistically meaningful according to any of the categories of the aesthetical appeal variables.

Regarding human figure, Mann-Whitney $U$ was performed, since it has two categories. The average number of likes of photos with figure dimension is 85.39 , while those that do not include it obtain 85.52 . Despite being a small difference, it is statistically significant according to the results of the Mann-Whitney test (Table 2).

Table 2. Non-parametric test results (dependent variable: likes).

\begin{tabular}{|c|c|c|c|c|c|c|}
\hline Variable & Categories & $\mathrm{n}$ & Mean Rank & Mann-Whitney U & Kruskal-Wallis H & Sig. \\
\hline \multirow{2}{*}{ Human dimension } & Presence & 29 & 55.64 & \multirow{2}{*}{1178.500} & \multirow{2}{*}{-} & \multirow{2}{*}{0.027} \\
\hline & Absence & 111 & 74.38 & & & \\
\hline \multirow{3}{*}{ Color } & Greyscale & 22 & 45.59 & \multirow{3}{*}{-} & \multirow{3}{*}{10.325} & \multirow{3}{*}{0.006} \\
\hline & Warm & 93 & 73.81 & & & \\
\hline & Cold & 25 & 80.12 & & & \\
\hline \multirow{3}{*}{ Linear perspective } & $1 \mathrm{VPP}$ & 57 & 86.25 & & \multirow{3}{*}{15.000} & \multirow{3}{*}{0.001} \\
\hline & $2 \mathrm{VPP}$ & 63 & 61.44 & - & & \\
\hline & 3VPP & 20 & 54.15 & & & \\
\hline \multirow{3}{*}{ Aesthetic quality } & Low & 60 & 67.60 & \multirow{3}{*}{ - } & \multirow{3}{*}{0.741} & \multirow{3}{*}{0.690} \\
\hline & Medium & 60 & 73.86 & & & \\
\hline & High & 20 & 69.13 & & & \\
\hline
\end{tabular}

Notes: $\mathrm{n}=$ sample (numer of Instagram photographs).

Since the other variables contain more than two categories, the Kruskal-Wallis test was applied. Regarding color, the average number of likes in grayscale is 33.91, in warm tones 87.52 and in cold 
tones 122.92, and there are significant differences $(p=0.006)$. Concerning perspective, 1VPP pictures receive an average of 86.25 likes, while 2VPP photos obtain 61.44 and 3VPP photos obtain 54.15 , and they have also shown significant differences $(p=0.001)$. Moreover, with regard to aesthetical quality, those images of low level obtain an average of 74.2 likes, those with a medium level obtain 94.46 and those of a high level obtain 67.68, without being correlated with significant differences $(p=0.690)$.

Next, Tukey's post hoc test (Table 3) was run to detect among which categories the significant differences arise. The results show these differences between images in grayscale and those in cold tones $(p=0.333)$ and between those with 1VPP and those with 2VPP $(p=0.049)$ (see Table 3$)$.

Table 3. Tukey test results (dependent variable: likes).

\begin{tabular}{cccccc}
\hline Variable & $(\mathbf{I})$ & $\mathbf{( J )}$ & Mean Difference (I-J) & Error Deviation & Sig. \\
\hline \multirow{2}{*}{ Color } & \multirow{2}{*}{ Grayscale } & Warm & -53.607 & 28.452 & 0.147 \\
& & Cold & -89.011 & 35.082 & 0.033 \\
\hline \multirow{2}{*}{ Linear perspective } & \multirow{2}{*}{ 1VPP } & 2 VPP & 51.685 & 22.015 & 0.049 \\
& & $2 V P P$ & 29.310 & 31.299 & 0.618 \\
\hline \multirow{2}{*}{ Aesthetical quality } & \multirow{2}{*}{ Low } & Medium & -20.267 & 22.354 & 0.637 \\
& & High & -17.700 & 31.613 & 0.842 \\
\hline
\end{tabular}

The same procedure was performed with the engagement variable (see Table 4). Engagement towards pictures with figure dimension obtains a mean value of 0.15 , while when it does not include it, the value drops to 0.12 , obtaining statistically meaningful differences $(p=0.019)$. Regarding color, the mean value of engagement in grayscale is $0.19,0.13$ in warm tone images and 0.14 in cold-tone images, without significant differences $(p=0.085)$. The linear perspective does show significant differences ( $p=0.038$ ) with mean engagement values of 0.16 in $1 \mathrm{VPP}, 0.14$ in 2VPP and 0.11 in 3VPP. Moreover, concerning aesthetic quality, no statistical differences were found ( $p=0.206)$ for mean engagement values of 0.13 in low cases, 0.16 in medium and 0.14 in high.

Table 4. Non-parametric test results (dependent variable: engagement).

\begin{tabular}{|c|c|c|c|c|c|c|}
\hline Variable & Categories & n & Mean Rank & Mann-Whitney U & Kruskal-Wallis H & Sig. \\
\hline \multirow{2}{*}{ Human dimension } & Presence & 29 & 54.81 & \multirow{2}{*}{1154.500} & \multirow{2}{*}{-} & \multirow{2}{*}{0.019} \\
\hline & Absence & 111 & 74.60 & & & \\
\hline \multirow{3}{*}{ Color } & Grayscale & 22 & 87.59 & \multirow{3}{*}{-} & \multirow{3}{*}{4.941} & \multirow{3}{*}{0.085} \\
\hline & Warm & 93 & 66.24 & & & \\
\hline & Cold & 25 & 71.30 & & & \\
\hline \multirow{3}{*}{ Linear perspective } & $1 \mathrm{VPP}$ & 57 & 80.46 & \multirow{3}{*}{-} & \multirow{3}{*}{6.565} & \multirow{3}{*}{0.038} \\
\hline & 2VPP & 63 & 65.87 & & & \\
\hline & 3VPP & 20 & 56.73 & & & \\
\hline \multirow{3}{*}{ Aesthetic quality } & Low & 60 & 63.54 & \multirow{3}{*}{ - } & \multirow{3}{*}{3.157} & \multirow{3}{*}{0.206} \\
\hline & Medium & 60 & 76.39 & & & \\
\hline & High & 20 & 73.70 & & & \\
\hline
\end{tabular}

Later, the Tukey test was applied to the linear perspective variable (see Table 5), obtaining that the statistical differences occur between 1VPP and 3VPP pictures $(p=0.048)$.

Table 5. Tukey test results (dependent variable: engagement).

\begin{tabular}{cccccc}
\hline Variable & $(\mathbf{I})$ & $\mathbf{( J )}$ & Mean Difference (I-J) & Error Deviation & Sig. \\
\hline \multirow{2}{*}{ Linear perspective } & \multirow{2}{*}{ 1VPP } & 2VPP & 0.0264 & 0.0163 & 0.243 \\
& & $3 \mathrm{VPP}$ & 0.0522 & 0.0233 & 0.048 \\
\hline
\end{tabular}




\section{Discussion and Conclusions}

The media and knowledge transfer have moved towards environments of social content creation that entail changes in the meaning of several subjects that had been widely agreed upon by academics. This study has focused on the vision of architectural heritage disseminated on Instagram and on the influence of graphic resources for its dissemination. It is important that science does not turn its back on these new media, and, above all, on their opportunities to promote heritage conservation.

The sample of images that was used corresponds to two types of users: stakeholders and regular users. In both cases, the visual message promotes building typologies such as residential, urban and religious. However, regular users foster a more heterogeneous view of this heritage. These user differences can be related to the purpose of the users in the IBSN. Those stakeholders may be seeking the protection of a specific typology of heritage, specifically residential buildings, while regular users do collaboratively contribute to visual creation. This trend of results is repeated in terms of the architectural elements that appear the most in photographs, highlighting facades, ruins, details, urban areas, windows and indoor environments. If the different users had not been considered, the absolute values of building typology and architectural element would be devastating, because a social image of the unreal building heritage would be described.

These findings cannot corroborate previous results on stakeholder intervention [24] since it has not been verified whether their mediation in the IBSN has changed the perception of Instagram users about heritage. However, it has been evidenced that they modify the architectural heritage visual message, which may have future consequences. This manifests a controversial issue about content control in open social environments; however, that is far from the scope of the investigation. Beyond controlling or allowing, it seems appropriate that international policies urge to complement heritage image in popular environments to avoid a biased one, instead of focusing on websites [25]. These results bring light on how an action of a positive nature (promoting heritage conservation) can lead to partially negative consequences, such as overshadowing other building typologies.

With regards to their dissemination, four aesthetical appeal variables were measured and analyzed: human figure, color, linear perspective and aesthetic quality. Images without figure dimension receive a greater number of likes and engagement, promoting an image of building heritage far from people's lives. A fact that opposes a result of direct relationship in previous findings [4]. Concerning color, those with a cool tone also obtain higher mean results of likes and engagement, which finds coherence among color and emotions [33]. This choice provides a more vivid vision of the heritage than through grayscale, which would seek a more distant perspective due to the temporal distance [34]. Concerning linear perspective and its ability to immerse in the picture, it has been shown that 1VPP photos obtain more likes and better engagement value. This result is consistent with the small size of the mobile devices used for IBSNs, since the vanishing points establish imaginary lines that guide the user's vision towards them and in the 2VPP and 3VPP, at least two points would be off the screen. Finally, aesthetical quality did not evidence statistical meaningful differences neither in likes nor engagement, being those classified as medium quality the ones that receive the greatest support in both dependent variables. These results support previous findings by Hsieh, Hsu and Wang [46] on a lack of value towards the aesthetic quality of the images.

This exploratory research provides a new approach to the use of IBSN content to describe how the perception of architectural heritage evolves and to what extent some resources of aesthetical appeal influence its degree of dissemination. The visual message is more disseminated in buildings' pictures with no human dimension, in cold tones, with one vanishing point perspective and with medium aesthetical quality, which promotes a far-away image of architectural heritage from people's life. A visual imaginary that could lead to the disappearance of social identity with heritage [12], based on a lack of sense of belonging or importance.

These results should not be misunderstood; the conservation of heritage does not directly depend on the number of likes or engagement of images. However, these dissemination variables allow us to address whether the visual representation of architecture in a picture influences it. 
Moreover, consequently, international institutions could consider them to enhance the scope of public dissemination policies in IBSNs. This practical application may seem poor, but it is usual that public institutions do not reach a large audience in these media, despite being well-known organizations.

The consequences of people's exposure to biased content will not be known for many years, but it seems that people's involvement in digital social environments deserves analysis and thought. A fact that is more necessary in cultural matters due to its disadvantaged character in times of economic crisis, especially when related to high-cost elements such as architecture. This novel nature entails some cons, such as the absence of references to this direct influence on society. However, recent research has called for the need for educational programs on architectural heritage "to increase children's awareness and to remind them of their role in its conservation while strengthening their cultural identity" [52].

This research seeks to anticipate the possible consequences that this situation may entail, so practical actions are proposed for the protection of architectural heritage:

- Public institutions dedicated to the conservation of architectural heritage should use image-based social networks such as Instagram in an educational way, since it is currently one of the most important social information carriers for youth. The change of platform involves adapting to how users experience it, rather than filling it with content. In this case, the use of own hasthtags and others from related communities should be encouraged to increase visibility towards networks with an interest in heritage that enhances social interaction.

- When promoting architectural heritage in image-based social networks, some aesthetic factors must be taken into account to produce images that can help reach a wider audience. The use of one vanishing point perspective is one of the most effective features due to the screen size where image-based social network runs, which entails positioning the point of interest within the device. However, other characteristics such as color and human dimension should not be a limitation in terms of its ability to spread. Instead, a criterion based on the feeling of closeness or cultural identity that they can convey should be considered, keeping in mind the objective of increasing population awareness towards architectural heritage.

- This research design is available to be replicated by governments and public institutions to diagnose to what extent its architectural heritage is visible in these media. Consequently, they should manage strategic plans to promote those elements with less visibility, without controlling the content generated by the population, but with the aim of complementing the information.

- This research can also serve as an example to trainers and teachers to educate students on how information can be biased in digital environments and how it can lead to the loss of an element as important as heritage.

This framework brings to light the need of future research on how the building image influences IBSN users, as well as how the way of approaching culture through digital photography (referring to the ephemeral habit of digital social networks) shapes people's feelings towards architectural heritage.

Author Contributions: Conceptualization, V.L.-C. and V.L.-P.; methodology, V.L.-C. and V.L.-P.; software, V.L.-C. and V.L.-P.; validation, V.L.-C.; formal analysis, V.L.-C.; investigation, V.L.-C. and V.L.-P.; resources, V.L.-C. and V.L.-P.; data curation, V.L.-C.; writing-original draft preparation, V.L.-C.; writing-review and editing, V.L.-C. and V.L.-P.; visualization, V.L.-C. All authors have read and agreed to the published version of the manuscript.

Funding: This research received no external funding.

Conflicts of Interest: The authors declare no conflict of interest.

\section{References}

1. Chen, H.; Kelliher, A. Conversational lives: Visualizing interpersonal online social interactions. In Lecture Notes in Computer Science (including subseries Lecture Notes in Artificial Intelligence and Lecture Notes in Bioinformatics); Springer: Berlin/Heidelberg, Germany, 2011.

2. Kessler, S. The Photo Economy. Fastcompany. Com. 2014, 190, 54-60. 
3. Martensen, A.; Brockenhuus-Schack, S.; Zahid, A.L. How citizen influencers persuade their followers. J. Fash. Mark. Manag. 2018, 22, 335-353. [CrossRef]

4. Bakhshi, S.; Shamma, D.A.; Gilbert, E. Faces engage us: Photos with faces attract more likes and comments on instagram. In Proceedings of the Conference on Human Factors in Computing Systems-Proceedings; ACM: Toronto, ON, Canada, 2014.

5. Casaló, L.V.; Flavián, C.; Ibáñez-Sánchez, S. Influencers on Instagram: Antecedents and consequences of opinion leadership. J. Bus. Res. 2020, 117, 510-519. [CrossRef]

6. Palazzo, M.; Vollero, A.; Vitale, P.; Siano, A. Urban and rural destinations on Instagram: Exploring the influencers' role in \#sustainabletourism. Land Use Policy 2021, 100, 104915. [CrossRef]

7. Schäfer, M.T. Bastard Culture! How User Participation Transforms Cultural Production; Amsterdam University Press: Amsterdam, The Netherlands, 2011.

8. Van Dijck, J. Flickr and the culture of connectivity: Sharing views, experiences, memories. Mem. Stud. 2011, 4, 401-415. [CrossRef]

9. Stepchenkova, S.; Kim, H.; Kirilenko, A. Cultural Differences in Pictorial Destination Images: Russia through the Camera Lenses of American and Korean Tourists. J. Travel Res. 2015, 54, 2015. [CrossRef]

10. Kennedy, L.; Naaman, M.; Ahern, S.; Nair, R.; Rattenbury, T. How flickr helps us make sense of the world: Context and content in community-contributed media collections. In Proceedings of the ACM International Multimedia Conference and Exhibition, Augsburg, Germany, 24-29 September 2007.

11. King, L.; Stark, J.F.; Cooke, P. Experiencing the Digital World: The Cultural Value of Digital Engagement with Heritage. Herit. Soc. 2016, 9, 76-101. [CrossRef]

12. Logan, W.; Wijesuriya, G. The New Heritage Studies and Education, Training, and Capacity-Building. In A Companion to Heritage Studies; Wiley: Hoboken, NJ, USA, 2015.

13. Giaccardi, E. Heritage and Social Media: Understanding Heritage in a Participatory Culture; Routledge: London, UK, 2012; ISBN 9780203112984.

14. Freeman, C.G. In the Eye of the Beholder. Arch. Des. 2020, 90, 88-93. [CrossRef]

15. Garduño Freeman, C. Photosharing on Flickr: Intangible heritage and emergent publics. Int. J. Herit. Stud. 2010, 16, 352-368. [CrossRef]

16. Anadol, R. Synaesthetic Architecture: A Building Dreams. Arch. Des. 2020, 90, 76-85. [CrossRef]

17. Naaman, M.; Song, Y.J.; Paepcke, A.; Garcia-Molina, H. Automatic organization for digital photographs with geographic coordinates. In Proceedings of the ACM IEEE International Conference on Digital Libraries, JCDL, Tucson, AZ, USA, 11 June 2004.

18. Mahmoudi Farahani, L.; Motamed, B.; Ghadirinia, M. Investigating heritage sites through the lens of social media. J. Arch. Urban. 2018, 42, 199-211. [CrossRef]

19. Al-Kodmany, K. Improving understanding of city spaces for tourism applications. Buildings 2019, 9, 187. [CrossRef]

20. Aigner, A. Heritage-making from below: The politics of exhibiting architectural heritage on the Internet-a case study. Int. J. Herit. Stud. 2016, 22, 181-199. [CrossRef]

21. Guerrero, P.; Møller, M.S.; Olafsson, A.S.; Snizek, B. Revealing cultural ecosystem services through instagram images: The potential of social media volunteered geographic information for urban green infrastructure planning and governance. Urban Plan. 2016, 1, 1-17. [CrossRef]

22. Song, Y.; Zhang, B. Using social media data in understanding site-scale landscape architecture design: Taking Seattle Freeway Park as an example. Landsc. Res. 2020, 45, 627-648. [CrossRef]

23. Ashley, C.; Tuten, T. Creative Strategies in Social Media Marketing: An Exploratory Study of Branded Social Content and Consumer Engagement. Psychol. Mark. 2015, 32, 15-27. [CrossRef]

24. De las Heras-Pedrosa, C.; Millan-Celis, E.; Iglesias-Sánchez, P.P.; Jambrino-Maldonado, C. Importance of social media in the image formation of tourist destinations fromthe stakeholders' perspective. Sustainablity 2020, 12, 4092. [CrossRef]

25. Vaughman Jones, Y.; Ostrouska, I. (Eds.) Promoting Access to Culture via Digital Means: Policies and Strategies for Audience Development; Publications Office of the European Union: Luxemburg, 2017.

26. Jansson, C.; Marlow, N.; Bristow, M. The influence of colour on visual search times in cluttered environments. J. Mark. Commun. 2004, 10, 183-193. [CrossRef]

27. Hinestroza, N.B.; James, P.T. The effects of sensory marketing on the implementation of fast-food marketing campaigns. J. Manag. Mark. Res. 2014, 14, 1-11. 
28. Amsteus, M.; Al-shaaban, S.; Wallin, E. Colors in Marketing: A Study of Color Associations and Context (in) Dependence. Int. J. Bus. Soc. Sci. 2015, 6, 3.

29. Yu, C.E.; Xie, S.Y.; Wen, J. Coloring the destination: The role of color psychology on Instagram. Tour. Manag. 2020, 80, 104110. [CrossRef]

30. Guntuku, S.C.; Roy, S.; Weisi, L. Personality modeling based image recommendation. In Lecture Notes in Computer Science (including subseries Lecture Notes in Artificial Intelligence and Lecture Notes in Bioinformatics); Springer: Berlin/Heidelberg, Germany, 2015.

31. Sorokowski, P.; Sorokowska, A.; Witzel, C. Sex differences in color preferences transcend extreme differences in culture and ecology. Psychon. Bull. Rev. 2014, 21, 1195-1201. [CrossRef] [PubMed]

32. Kim, J.H.; Kim, Y. Instagram user characteristics and the color of their photos: Colorfulness, color diversity, and color harmony. Inf. Process. Manag. 2019, 56, 1494-1505. [CrossRef]

33. Amencherla, M.; Varshney, L.R. Color-based visual sentiment for social communication. In Proceedings of the 2017 15th Canadian Workshop on Information Theory, CWIT, Quebec, QC, Canada, 11-14 June 2017.

34. Peláez Becerra, S.M.; Gómez Gómez, P.; Becerra, M.A. Emociones cromáticas: Análisis de la percepción de color basado en emociones y su relación con el consumo de moda. Anagramas-Rumbos Y Sentidos Comun. 2016, 14, 83-96. [CrossRef]

35. Wartofsky, M.; Arnheim, R. Entropy and Art: An Essay on Disorder and Order. J. Aesthet. Art Crit. 1973, 32, 280-281. [CrossRef]

36. Wilson, A.; Chatterjee, A. The Assessment of Preference for Balance: Introducing a New Test. Empir. Stud. Arts 2005, 23, 165-180. [CrossRef]

37. Bauerly, M.; Liu, Y. Computational modeling and experimental investigation of effects of compositional elements on interface and design aesthetics. Int. J. Hum. Comput. Stud. 2006, 64, 670-682. [CrossRef]

38. McManus, I.C. Balance in pictures. Br. J. Psychol. 1985, 64, 670-682. [CrossRef]

39. Hübner, R.; Fillinger, M.G. Comparison of objective measures for predicting perceptual balance and visual aesthetic preference. Front. Psychol. 2016, 7, 335. [CrossRef]

40. Islam, M.B.; Lai-Kuan, W.; Chee-Onn, W. A survey of aesthetics-driven image recomposition. Multimed. Tools Appl. 2017, 76, 9517-9542. [CrossRef]

41. Liu, L.; Chen, R.; Wolf, L.; Cohen-Or, D. Optimizing photo composition. Comput. Graph. Forum 2010, 29, 469-478. [CrossRef]

42. Makin, A.D.J.; Pecchinenda, A.; Bertamini, M. Implicit affective evaluation of visual symmetry. Emotion 2012, 12, 1021-1030. [CrossRef] [PubMed]

43. Itti, L.; Koch, C.; Niebur, E. A model of saliency-based visual attention for rapid scene analysis. IEEE Trans. Pattern Anal. Mach. Intell. 1998, 20, 1254-1259. [CrossRef]

44. Bruno, N.; Bertamini, M.; Tyler, C.W. Eye centring in selfies posted on Instagram. PLoS ONE 2019, 14, e0218663. [CrossRef] [PubMed]

45. Thömmes, K.; Hübner, R. Instagram likes for architectural photos can be predicted by quantitative balance measures and curvature. Front. Psychol. 2018, 9, 1050. [CrossRef] [PubMed]

46. Hsieh, L.C.; Hsu, W.H.; Wang, H.C. Investigating and predicting social and visual image interestingness on social media by crowdsourcing. In Proceedings of the ICASSP, IEEE International Conference on Acoustics, Speech and Signal Processing-Proceedings, Florence, Italy, 4-9 May 2014.

47. Thömmes, K.; Hübner, R. Why People Press "Like": A New Measure for Aesthetic Appeal Derived from Instagram Data. Psychol. Aesthet. Creat. Arts 2020, 1-18. [CrossRef]

48. Pierce, J.S. Architectural Drawings and the Intent of the Architect. Art J. 1967, 27, 48-59. [CrossRef]

49. Meraz, J.M.F. Inhabited graphic space: The human figure in architectural visual communication. Arquiteturarevista 2015, 11, 31. [CrossRef]

50. Anderson, A.T. On the human figure in architectural representation. J. Archit. Educ. 2002, 55, $238-246$. [CrossRef]

51. Lozanovska, M. Uomo universale: The imaginary relation between body and mathematic(s) in architecture. Archit. Theory Rev. 2009, 14, 234-247. [CrossRef] 
52. Çiftçi, A. Impact of Historic Environments on Child's Cultural Identity and Architectural Heritage Awareness: C.A.T.C.H. (Children-Architects to Create Homes), Erasmus + Project Experience. Hist. Env. Policy Pr. 2020, 11, 127-157. [CrossRef]

Publisher's Note: MDPI stays neutral with regard to jurisdictional claims in published maps and institutional affiliations.

(C) 2020 by the authors. Licensee MDPI, Basel, Switzerland. This article is an open access article distributed under the terms and conditions of the Creative Commons Attribution (CC BY) license (http://creativecommons.org/licenses/by/4.0/). 